\title{
Evaluation of the congenital air way malformation in children with congenital heart disease using cardiac MR
}

Ming Zhu

From 18th Annual SCMR Scientific Sessions

Nice, France. 4-7 February 2015

\section{Background}

The cardiovascular magnetic resonance (CMR) is usually complements echocardiography, provides a non- ionizing radiation evaluation of congenital heart disease(CHD). The congenital air way malformation occur significantly more patients with CHD than patients without CHD. Echocardiography can not show air way well and CT can show air way very well. MRI has emerged as a powerful approach to imaging CHD in children. The question is if MRI is good enough for showing air way malformation.

\section{Methods}

We review our 428 MR cases of CHD in 2014. CMR was performed using a $1.5 \mathrm{~T}$ unit(Achieva Nova dual; Philips). The range of age in 428 patients was 10 days to 12 years (mean 3.2 years). Imaging sequences included ECGtriggered 2D balanced steady state free precession (b-SSFP) Cine, phase contrast sequences cine (PC Cine), ECGtriggered 2D Spin echo black blood, Contrast-enhanced 3D magnetic resonance angiography (CE-MRA), Navigatorgated, ECG-triggered 3D balanced steady state free precession (SSFP) MRA and Navigator-gated, ECG-triggered 3D T1W TFE sequences. Minimum-intensity (MinIP) reconstruction was used to evaluate the tracheobronchial tree in CE-MRA, 3D SSFP and 3D T1W TFE sequences.

\section{Results}

The tracheobronchial tree can be visualized clearly in $82.7 \%(286 / 348)$ of CE-MRA sequences, in $92.6 \%$ (224/ 242) of 3D SSFP sequences and in $98.7 \%(155 / 157)$ of 3D T1W TFE sequences.

In 36 of the $428(8.4 \%)$ cases with CHD, congenital air way malformation observed in MRI. The congenital air

Radiology Dept., Shanghai Children's Medical Center, Shanghai, China way malformation include tracheal bronchus 18 , asplenia syndrome 7 (bilateral right bronchi), polysplenia syndrome 3 (bilateral left bronchi), congenital tracheal stenosis 3 , bridging bronchus 3 and bilateral tracheal bronchi with asplenia syndrome 2 cases. The bilateral tracheal bronchi with asplenia syndrome is very rare congenital air way malformation.

\section{Conclusions}

This data shows that congenital air way malformation is common in children with CHD. Our data also means that MRI also can show tracheobronchial tree and navigator-gated, ECG-triggered 3D T1W TFE sequences and MinIP reconstruction is the best sequences for air way.

Published: 3 February 2015

doi:10.1186/1532-429X-17-S1-P217

Cite this article as: Zhu: Evaluation of the congenital air way malformation in children with congenital heart disease using cardiac MR. Journal of Cardiovascular Magnetic Resonance 2015 17(Suppl 1):P217.

Submit your next manuscript to BioMed Central and take full advantage of:

- Convenient online submission

- Thorough peer review

- No space constraints or color figure charges

- Immediate publication on acceptance

- Inclusion in PubMed, CAS, Scopus and Google Scholar

- Research which is freely available for redistribution 